\title{
CRESCIMENTO E NUTRIÇÃO MINERAL DO PORTA-ENXERTO LIMOEIRO 'CRAVO’ CULTIVADO EM SUBSTRATO COM ZEÓLITA ENRIQUECIDA COM NPK ${ }^{1}$
}

\author{
ALBERTO CARLOS DE CAMPOS BERNARDI²,CARLOS GUARINO WERNECK ${ }^{3}$,PATRICK GESUALDI HAIM ${ }^{3}$, \\ NÉLIO DAS GRAÇAS DE ANDRADE DAMATA REZENDE ${ }^{4}$, PAULO RENATO PERDIGÃO PAIVA $^{5}$, \\ MARISA BEZERRA DE MELLO MONTE 5
}

RESUMO- O objetivo do trabalho foi avaliar o efeito da adição de um concentrado zeolítico enriquecido com N, P e K ao substrato de cultivo sobre o crescimento, produção de matéria seca, área foliar, teores e extração de N, P e K e os teores de clorofila do limoeiro 'Cravo'. O porta-enxerto foi cultivado por 93 dias em tubetes de $150 \mathrm{~cm}^{3}$ com substrato orgânico compostado de casca de coco e carvão vegetal (3:1) ao qual se adicionou o concentrado zeolítico. Este foi obtido com a concentração da zeólita natural (Z) e enriquecimento desta com $\mathrm{KNO}_{3}(\mathrm{ZNK})$, e também com a acidificação com $\mathrm{H}_{3} \mathrm{PO}_{4}$ e mistura com apatita (ZP). Utilizou-se uma mistura de 30\%ZNK + 70\% ZP nas doses de: $0 ; 2,5 ; 5 ; 10$ e $15 \mathrm{~g}$ por planta. Os resultados indicaram que o fornecimento de nutrientes através do mineral zeólita adicionado ao substrato orgânico comprovou ser alternativa viável para a obtenção de porta-enxertos no sistema de produção em ambiente protegido. A adição de 6,4 g do concentrado zeolítico enriquecido com NPK aumentou significativamente a produção de matéria seca, área foliar, altura e diâmetro de caule. Este aumento foi de 37,5\% em relação à testemunha que não recebeu o concentrado zeolítico. Houve aumentos nos teores e extração de N, P e K com o fornecimento da zeólita enriquecida. As leituras dos teores de clorofila relacionaram-se com os teores de $\mathrm{N}$, indicando ser esta uma alternativa para o diagnóstico do estado nutricional para a cultura.

Termos para indexação: Citrus limonia, estilbita, diagnose foliar, fertilizante de liberação lenta.

\section{GROWTH AND MINERAL NUTRITION OF RANGPUR LIME ROOTSTOCK CULTIVATED IN SUBSTRATE WITH ZEOLITE ENRICHED WITH NPK}

\begin{abstract}
The main objective of this research was to evaluated the growth, dry matter production, leaf area, N, P and K levels and exportation and chlorophyll levels of Rangpur Lime (Citrus limonia Osbeck) grown in a substrate with NPK enriched zeolite. Rootstocks were cultivated during 93 days in $150 \mathrm{~cm}^{3}$-dibble tubes containing composted organic substrate of cocopeat and vegetal coal (3:1) with zeolite addition. Treatments comprised 4 levels $(0,2.5,5,10$ and $15 \mathrm{~g}$ per plant) of a NPK-enriched zeolite, which was a mix of $\mathrm{H}_{3} \mathrm{PO}_{4}$ /apatite-zeolite $(70 \%)$ and $\mathrm{KNO}_{3}$-zeolite $(30 \%)$. Results indicated that the supply of nutrients through the mineral zeolite enriched with NPK added to the organic substrate was a viable alternative for citrus rootstock production in protecting environment. The supply of $6,4 \mathrm{~g}$ of enriched zeolite significantly increased dry matter production, leaf area, height and steam diameter. These increases were $37,5 \%$ in relation to the control without zeolite. N, P and K foliar levels increased with zeolite enriched with NPK. Chlorophyll levels were related to $\mathrm{N}$ levels, pointed out to be a useful tool for Rangpur Lime nutritional status evaluation. Index Terms: Citrus limonia, stilbite, foliar diagnosis, slow-release fertilizer.
\end{abstract}

\section{INTRODUÇÃO}

As normas para produção de mudas certificadas de citros, do Estado de São Paulo, obrigatoriamente prevêem que estas sejam produzidas em ambiente protegido contra vetores de doenças, em recipientes com substrato isento de patógenos e de propágulos de plantas daninhas, a partir de sementes e borbulhas certificadas, e a adoção de medidas para evitar a incidência de cancro-cítrico, clorose variegada dos citros, gomose e mancha-preta (Carvalho, 1998; Coordenadoria de Assistência Técnica Integral - CATI, 1998).
Este sistema de produção de mudas, além de melhorar as condições fitossanitárias, visa também a promover crescimento mais rápido e a padronizar o processo de formação dos porta-enxertos e mudas. Há grande crescimento das plantas em curto espaço de tempo e em volume restrito para o desenvolvimento do sistema radicular. Portanto, o fornecimento de nutrientes em doses adequadas e balanceadas, no período de maior exigência das plantas, é necessário para estimular o máximo crescimento, além de reduzir as perdas por lixiviação.

1(Trabalho 244-07). Recebido em: 05-10-2007. Aceito para publicação em: 20-06-2008.

${ }^{2}$ Embrapa Pecuária Sudeste, Rod. Washington Luiz km 234, Cx. Postal 339, São Carlos-SP CEP: 13560-970. E-mail: alberto@cppse.embrapa.br. ${ }^{3}$ Universidade Federal Rural do Rio de Janeiro - UFRRJ, Seropédica-RJ;

${ }^{4}$ CPRM, Belém-PA;

${ }^{5}$ Laboratório de Química de Superfície - Centro de Tecnologias Minerais - CETEM, Rio de Janeiro-RJ.

Rev. Bras. Frutic., Jaboticabal - SP, v. 30, n. 3, p. 794-800, Setembro 2008 
Estudos realizados com fornecimento de fertilizantes aos porta-enxertos (Rezende et al., 1995; Carvalho et al., 2000; Bernardi et al., 2000 a, b; DeCarlos Neto et al., 2002; Ruschel et al., 2004; Esposti \& Siqueira, 2004; Scivittaro et al., 2004) indicaram as doses mais adequadas para obtenção de crescimento máximo das plantas.

A adubação dos porta-enxertos e das mudas pode ser realizada através do pré-enriquecimento com fertilizantes de liberação lenta, fertirrigação, adubação de cobertura e adubação foliar (Coetzee et al., 1993). Existe também nova possibilidade, que é a adição de minerais zeolíticos ao substrato (Leggo, 2000; Harland et al., 1999; Mercadet et al., 1990 a, b).

Zeólitas são minerais alumino-silicatos cristalinos, hidratados de metais alcalinos ou alcalinos-terrosos, estruturados em redes cristalinas tridimensionais rígidas, formadas por tetraedros de $\mathrm{AlO}_{4}$ e $\mathrm{SiO}_{4}$, cujos anéis, ao se unirem, compõem sistema de canais, cavidades e poros (Mumpton, 1999). Estes minerais zeolíticos apresentam propriedades que lhes conferem grande interesse para uso na agricultura, que são a alta capacidade de troca de cátions, alta capacidade de retenção de água livre nos canais e a alta habilidade na adsorção de íons. A zeólita pode atuar na melhoria da eficiência do uso de nutrientes através do aumento da disponibilidade de $\mathrm{P}$ da rocha fosfática, e na melhora do aproveitamento do $\mathrm{N}\left(\mathrm{NH}_{4}^{+} \mathrm{e} \mathrm{NO}_{3}^{-}\right)$e redução das perdas por lixiviação dos cátions trocáveis, especialmente $\mathrm{K}^{+}$ (Barbarick et al., 1990; Allen et al., 1995; Williams \& Nelson, 1997; Leggo, 2000; e Pickering et al., 2002). As zeólitas misturadas a rochas fosfáticas podem funcionar como sistema de liberação controlada e renovável de nutrientes para as plantas (Allen et al., 1995; Barbarick et al., 1990). De acordo com Leggo (2000), em função da afinidade da zeólita por nutrientes, este mineral pode ser utilizado em substratos orgânicos para estimular o crescimento das plantas. Mercadet et al. (1990 a, b), em Cuba, observaram efeitos positivos da adição de $20 \%$ de zeólita ( $180 \mathrm{~g}$ por recipiente) sobre o crescimento de seedlings de Pinus caribaea e Eucalyptus pellita.

O objetivo deste trabalho foi avaliar o efeito da adição ao substrato de cultivo, de um concentrado zeolítico enriquecido com N, P e K, sobre o crescimento, produção de matéria seca, área foliar, teores e extração de N, P e K e teores de clorofila do limoeiro 'Cravo'.

\section{MATERIAL E MÉTODOS}

O experimento foi conduzido em casa de vegetação, utilizando-se de tubetes com substrato orgânico e adição de concentrado zeolítico, entre setembro e dezembro. As plantas utilizadas foram obtidas por germinação de sementes do portaenxerto limoeiro 'Cravo' (Citrus limonia Osbeck), retiradas de frutos maduros oriundos de plantas sadias do pomar de matrizes de porta-enxertos do Centro APTA Citros 'Sylvio Moreira', Cordeirópolis-SP. Cada tubete recebeu $150 \mathrm{~cm}^{3}$ de substrato e foi cultivado com uma única planta. A irrigação diária foi realizada manualmente com água pura.

O substrato orgânico utilizado foi mistura de casca de coco e carvão vegetal, na relação de 3:1(v/v), compostado por 90 dias. Sua composição química revelou: $\mathrm{N}, 11,26 \mathrm{~g} \mathrm{~kg}^{-1} ; \mathrm{P}, 8,04 \mathrm{~g}$ $\mathrm{kg}^{-1} ; \mathrm{K}, 7,61 \mathrm{~g} \mathrm{~kg}^{-1} ; \mathrm{Ca}, 7,98 \mathrm{~g} \mathrm{~kg}^{-1} ; \mathrm{Mg}, 2,00 \mathrm{~g} \mathrm{~kg}^{-1} ; \mathrm{S}, 1,37 \mathrm{~g} \mathrm{~kg}^{-1}$; $\mathrm{Cu}, 7,0 \mathrm{mg} \mathrm{kg}^{-1} ; \mathrm{Fe}, 8,7 \mathrm{~g} \mathrm{~kg}^{-1}$; Mn , $396 \mathrm{mg} \mathrm{kg}^{-1} ; \mathrm{Zn}, 29,2 \mathrm{mg} \mathrm{kg}^{-1}$, e Na, $1,78 \mathrm{~g} \mathrm{~kg}^{-1}$.

A zeólita utilizada foi coletada na Bacia do Parnaíba, no Maranhão, a qual representa o principal depósito de zeólita natural do País (Rezende \& Angélica, 1991). O material coletado foi concentrado em mesa vibratória, resultando em produto com $84 \%$ de zeólita estilbita e com capacidade de troca de cátions de 2,5 $\mathrm{cmol}_{\mathrm{c}} \mathrm{g}^{-1}$. A fórmula química determinada da zeólita foi: $(\mathrm{CaO})_{0,82}\left(\mathrm{Na}_{2} \mathrm{O}\right)_{0,19}\left(\mathrm{~K}_{2} \mathrm{O}\right)_{0,15}(\mathrm{MgO})_{0,56}\left(\mathrm{Fe}_{2} \mathrm{O}_{3}\right)_{0,30}\left(\mathrm{TiO}_{2}\right)_{0.11}$ $\left(\mathrm{Al}_{2} \mathrm{O}_{3}\right)_{1,85}\left(\mathrm{SiO}_{2}\right)_{16}\left(\mathrm{H}_{2} \mathrm{O}\right)_{4,7}$. A zeólita concentrada foi enriquecida, através da incubação, com soluções contendo $\mathrm{H}_{3} \mathrm{PO}_{4} 1,0 \mathrm{~mol} \mathrm{~L}$ ${ }^{1}$ (ZP) e $\mathrm{KNO}_{3} 0,5 \mathrm{~mol} \mathrm{~L}^{-1}$ (ZNK). A relação utilizada foi de 1:40 (zeólita/solução, $\mathrm{m} / \mathrm{v}$ ), por 24 horas, com temperatura e agitação constantes. Após a incubação, a suspensão foi filtrada, e o material sólido, desidratado a $100^{\circ} \mathrm{C}$. A zeólita enriquecida com $\mathrm{H}_{3} \mathrm{PO}_{4}$ recebeu a adição de fosfato natural $\left(34 \%\right.$ de $\left.\mathrm{P}_{2} \mathrm{O}_{5}\right)$, na proporção de 2:1 (zeólita/fosfato, $\mathrm{m} / \mathrm{m}$ ). As concentrações, determinadas no extrato da pasta de saturação (Embrapa, 1997), de $\mathrm{N}$ e $\mathrm{K}$ na mistura ZNK eram 21180 e $15210 \mathrm{mg} \mathrm{kg}^{-1}$, respectivamente, e de $\mathrm{P}$ na mistura $\mathrm{ZP}, 7130 \mathrm{mg} \mathrm{kg}^{-1}$.

Utilizou-se uma mistura de $30 \% \mathrm{ZNK}+70 \% \mathrm{ZP}$ nas doses de: $0 ; 2,5 ; 5 ; 10$ e $15 \mathrm{~g}$ por planta. Todos os tratamentos receberam quantidades do concentrado zeolítico para completar $15 \mathrm{~g}$ por planta, o qual representava $30 \%$ do peso do substrato. Houve ainda uma testemunha absoluta cultivada apenas no substrato orgânico, sem adição do concentrado zeolítico enriquecido com NPK. O delineamento experimental foi o inteiramente casualizado, com 4 repetições.

Quinzenalmente, foram realizadas medidas do diâmetro do caule e altura das plantas. Ao final de 93 dias de cultivo, no período entre 9 e 10 horas, determinou-se o teor de clorofila com o clorofilômetro (Chlorophyll Meter SPAD-502 Minolta Co., Japão), nas folhas recém-maduras, fora da nervura central, procedendo-se a três medidas consecutivas no mesmo ponto. Então, as plantas foram retiradas dos recipientes, e as imagens das folhas foram capturadas com câmera digital e analisadas utilizando o programa SIARCS 3.0 - Sistema Integrado para Análise de Raízes e Cobertura do Solo (Crestana et al., 1994) para obtenção de área foliar. Em seguida, as partes das plantas foram lavadas e secas em estufa com circulação forçada de ar a $65^{\circ} \mathrm{C}$ e pesadas. Foram realizadas avaliações da produção de matéria seca das folhas, caule, raízes e total.

Determinaram-se os teores dos macronutrientes N, P e K nos tecidos, seguindo a metodologia de Carmo et al. (2000). Os teores totais de $\mathrm{N}$, no extrato da digestão sulfúrica, foram determinados pelo método semimicro Kjeldhal. Os teores de $\mathrm{Pe}$ $\mathrm{K}$, no extrato da digestão nitroperclórica, foram determinados por espectrometria de plasma induzido (ICP-OES) e fotometria de chama, respectivamente.

Realizou-se a análise de variância, e foram ajustadas equações de regressão para as variáveis analisadas em função das doses de concentrado zeolítico. Estabeleceu-se também o coeficiente de correlação linear entre os teores de $\mathrm{N}$ e as leituras SPAD. 


\section{RESULTADOS E DISCUSSÃO}

Os resultados obtidos para produção de matéria seca estão na Figura 1. Os valores máximos da produção de matéria seca das folhas, caule, raízes (Figura 1A), parte aérea e total (Figura 1B) do porta-enxerto limoeiro 'Cravo' foram 0,62; 0,41; 0,$50 ; 1,03$ e $1,58 \mathrm{~g}$ por planta, obtidos, respectivamente, nas doses de 6,$7 ; 6,2 ; 6,1 ; 6,4$ e 6,3 g por planta de concentrado zeolítico enriquecido com NPK. Observou-se que a adição, em média, de 6,3 do concentrado zeolítico enriquecido com NPK aumentou $42 \%$ as produções de matéria seca em relação à testemunha absoluta, que não recebeu o concentrado zeolítico. Os resultados obtidos por Leggo (2000) também demonstraram que plantas cultivadas em substrato orgânico com zeólita enriquecida com $\mathrm{N}$-amoniacal apresentaram produção de matéria seca $19 \%$ maior que outras cultivadas sem a adição do mineral. Mercadet et al. (1990 a, b) obtiveram efeitos positivos sobre a altura de seedlings de Pinus caribaea e Eucalyptus pellita com a adição de $20 \%$ de zeólita (180 g) ao substrato de cultivo. Pickering et al. (2002) também observaram aumentos na absorção de fósforo por plantas de girassol cultivadas em substrato com zeólita em mistura com rocha fosfática.

Na dose média de melhor resposta, 6,3 g por planta de concentrado zeolítico enriquecido com NPK, os níveis de N, P e $\mathrm{K}$ nos vasos eram 269; $210 \mathrm{e}^{193} \mathrm{mg} \mathrm{dm}^{-3}$, respectivamente. Esses valores são semelhantes aos normalmente utilizados em soluções nutritivas, por isso foram observadas respostas crescentes até esta dose, e decréscimo nas doses superiores (10 e 15 g por planta de concentrado zeolítico enriquecido com NPK), provavelmente devido a teores excessivos dos íons nitrato e potássio. Os decréscimos na produçõa de matéria seca, nas doses mais altas de nutrientes, também foram observados por Bernardi et al. (2000a) e Ruschel et al.(2004).

A relação raízes/parte aérea é útil para estudar-se o equilíbrio entre a produção de raízes e folhas, devido às modificações no ambiente, uma vez que indica a existência de uma interdependência entre os órgãos no balanço por água, nutrientes e carbono. Quando há baixa disponibilidade de nutrientes, há menor crescimento da parte aérea, e as raízes são longas e sem divisões. Nos níveis intermediários, há desenvolvimento e divisão adequados do sistema radicular. Com níveis altos de nutrientes, observa-se elevada divisão das raízes, porém o sistema radicular é reduzido e há estímulo para o desenvolvimento da parte aérea. A relação parte aérea/raiz máxima $(2,3)$ foi obtida na dose de 7,3 g por planta de concentrado zeolítico. Esses valores estão próximos dos obtidos por Bernardi et al. (2000a) para o mesmo porta-enxerto.

O diâmetro do caule tem relação direta com a altura das plantas (Bernardi et al., 2000a), e é a característica morfológica do porta-enxerto que determina a possibilidade de realização da enxertia. A Figura 2 mostra a interação positiva entre as doses de concentrado zeolítico enriquecido com NPK e os dias de cultivo para ambas características do limoeiro 'Cravo'. Os resultados indicaram que, próximo da dose de $6,3 \mathrm{~g}$ por planta de concentrado zeolítico enriquecido com NPK, obtiveram-se as maiores alturas e diâmetros. A Figura 3 ilustra a altura e os diâmetros ao final do experimento (93 dias). Os resultados obtidos mostram que houve efeito quadrático das doses de concentrado zeolítico enriquecido com NPK, sendo que os maiores valores (13,2 cm e 4,4 mm) foram obtidos com as doses de 5,7 e 6,7 g por planta. Os resultados de altura de plantas variaram de 116,38 a $125,32 \mathrm{~cm}$, com a altura máxima $(128,84 \mathrm{~cm})$ obtida com a dose de $3,19 \mathrm{~g}$ por planta.

A média das doses de melhor resposta, em termos de produção de matéria seca, foi de $6,4 \mathrm{~g}$ por planta da mistura de concentrado zeolítico $(0,3 \mathrm{ZNK}+0,7 \mathrm{ZP})$, que representaram aumentos de $37,5 \%$ em relação à testemunha. Nesta dose média, as quantidades de $\mathrm{N}, \mathrm{P}$ e $\mathrm{K}$ fornecidas para as plantas foram, respectivamente, 135,5; 97,3 e 45,6 $\mathrm{mg} \mathrm{g}^{-1}$, ou 814; 639e $584 \mathrm{~g} \mathrm{dm}^{-3}$, considerando-se o volume dos tubetes $\left(150 \mathrm{~cm}^{3}\right)$. Scivittaro et al. (2004) obtiveram efeitos positivos da dose de $\mathrm{N}$ de $1.050 \mathrm{mg} \mathrm{dm}^{-}$ ${ }^{3}$ sobre a produção de matéria seca da parte aérea, altura e diâmetro do caule do porta-enxerto limoeiro 'Cravo'. Já Esposti \& Siqueira (2004) observaram que doses menores de N (453 mg $\left.\mathrm{dm}^{-3}\right)$, aplicadas na forma de uréia, levaram às melhores respostas. Nos viveiros da África do Sul, são utilizados entre 0,32 e 0,42 g $\mathrm{dm}^{-3}$ de P como superfosfato simples (Coetzee et al., 1993), valores inferiores aos da resposta obtida neste trabalho; porém deve ser considerado que essas doses são aplicadas no transplantio e, posteriormente, as plantas recebem adubação NPK complementar durante o desenvolvimento. Rezende et al. (1995) verificaram maior desenvolvimento de limoeiro 'Cravo' quando utilizaram doses em torno de $2,5 \mathrm{~g} \mathrm{dm}^{-3}$ de $\mathrm{P}$ no substrato de cultivo. Miller et al. (1993), trabalhando com 5 porta-enxertos de citros, também obtiveram aumentos na produção do material seco total das plantas com o fornecimento de $\mathrm{K}$ na solução nutritiva até uma dose intermediária (150 $\left.\mathrm{mg} \mathrm{L}^{-1}\right)$; entretanto, quando elevaram a dose para $300 \mathrm{mg} \mathrm{L}^{-1}$ não houve resposta. Já Carvalho et al. (2000) observaram aumentos lineares dos crescimento dos portaenxertos até a dose de $3 \mathrm{~g} \mathrm{~L}^{-1}$ de $\mathrm{KNO}_{3}$ aplicada semanalmente até 150 dias.

A determinação da área foliar é importante, porque as folhas são as principais responsáveis pela captação da energia solar e pela produção de material orgânico através da fotossíntese. Os resultados obtidos mostraram que houve influência do fornecimento de nutrientes pelo concentrado zeolítico na área foliar do limoeiro 'Cravo'. A Figura 4 mostra que a área foliar máxima $\left(75,22 \mathrm{~cm}^{2}\right)$ foi obtida na dose de $6,9 \mathrm{~g}$ por planta. Bernardi et al. (2000a) também observaram as maiores áreas foliares nos níveis intermediários de adubação.

Os resultados positivos do fornecimento do concentrado zeolítico enriquecido com NPK no substrato de cultivo confirmam ser este adequada fonte de nutrientes para as plantas, como o relatado por Leggo (2000), com substratos organominerais com zeólita, e por Barbarick et al. (1990), Allen et al. (1995) e Pickering et al. (2002) com a mistura de zeólita com rocha fosfática.

O teor de nutrientes nos tecidos vegetais reflete sua disponibilidade no substrato de cultivo, pois existe relação entre o fornecimento de um nutriente pelo substrato de cultivo ou por um fertilizante e a concentração na folha, e uma relação entre essa concentração e a produção da cultura (Malavolta et al., 1997). Os resultados, na Figura 5A, indicam que houve comportamento quadrático dos teores de $\mathrm{N}$ nas folhas do limoeiro 
'Cravo' com ponto de inflexão na dose de 9,2 g por planta do concentrado zeolítico, que proporcionou o teor de $15,4 \mathrm{~g} \mathrm{~kg}^{-1}$. Já os resultados dos teores de $\mathrm{Pe} \mathrm{K}$, na mesma Figura, indicam que houve aumentos lineares de 1,99 a $2,98 \mathrm{~g} \mathrm{~kg}^{-1} \mathrm{e} 14,9$ a $18,4 \mathrm{~g} \mathrm{~kg}^{-1}$, respectivamente, com o aumento das doses de zeólita enriquecida.

O princípio da diagnose foliar é comparar a concentração de nutrientes nas folhas com valores-padrão, correspondentes às variedades ou espécies de alta produtividade e com desenvolvimento vegetativo adequado (Malavolta et al., 1997). Desse modo, os valores de N e K estão abaixo dos encontrados por Carvalho et al. (2000), Bernardi et al. (2000b) e Ruschel et al. (2004) para a mesma espécie. Já os teores de P foram equivalentes aos encontrados por Carvalho et al. (2000) e inferiores aos encontrados pelos outros autores citados.

Com relação à extração (Figura 5B), houve efeito quadrático para os macronutrientes $\mathrm{N}, \mathrm{Pe} \mathrm{K}$, sendo que as maiores extrações $(16,1 ; 5,8$ e 21,5 mg por planta) ocorreram nas doses de 6,2; 7,5 e 6,7 g de zeólita por planta, respectivamente, indicando

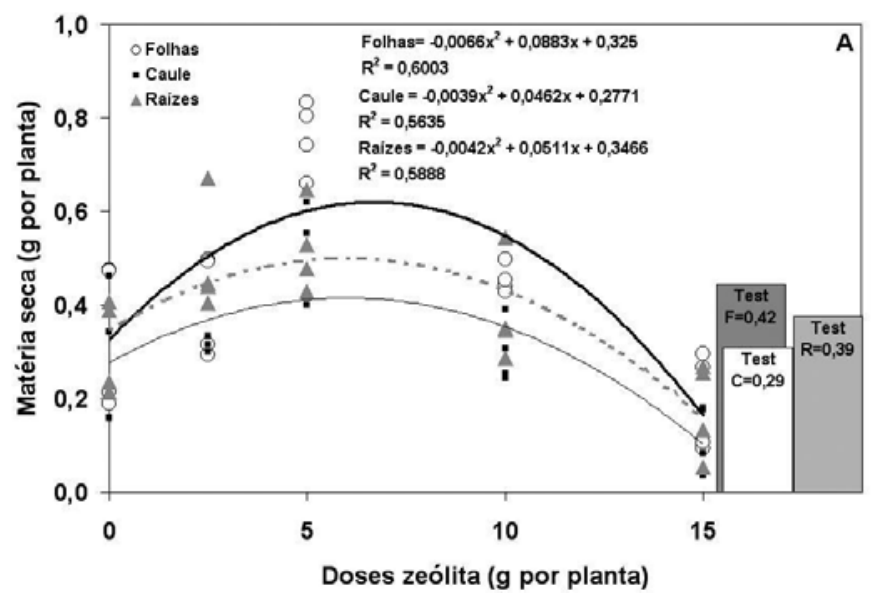

que houve absorção dos nutrientes presentes no concentrado zeolítico enriquecido com $\mathrm{N}$, rocha fosfática e $\mathrm{K}$, como nos trabalhos de Barbarick et al. (1990), Allen et al. (1995), Willians \& Nelson (1997), Leggo (2000) e Pickering et al. (2002).

As leituras do clorofilômetro oferecem rápida e nãodestrutiva estimação dos teores de clorofila nas folhas. Na Figura 6 A, observa-se o comportamento quadrático dos valores das leituras SPAD em função das doses de concentrado zeolítico. O maior valor $(47,9)$ foi obtido com a dose de $8,1 \mathrm{~g}$ por planta.

Entre 50 e $70 \%$ do $\mathrm{N}$ total na folha está associado a enzimas presentes nos cloroplastos, por isso existe relação direta entre o teor de $\mathrm{N}$ e o conteúdo de clorofila (Esposti et al., 2003). Os resultados obtidos neste trabalho confirmam os autores, uma vez que os teores de clorofila medidos pelo clorofilômetro SPAD foram influenciados pelos teores de $\mathrm{N}$ e houve correlação positiva entre os teores de $\mathrm{N}$ na folha do limoeiro 'Cravo' e os teores de clorofila, com coeficiente de correlação $r=0,701$ (Figura 6B), indicando, com isso, que essa medida pode funcionar como diagnóstico do estado nutricional desse nutriente no portaenxerto limoeiro ‘Cravo'.

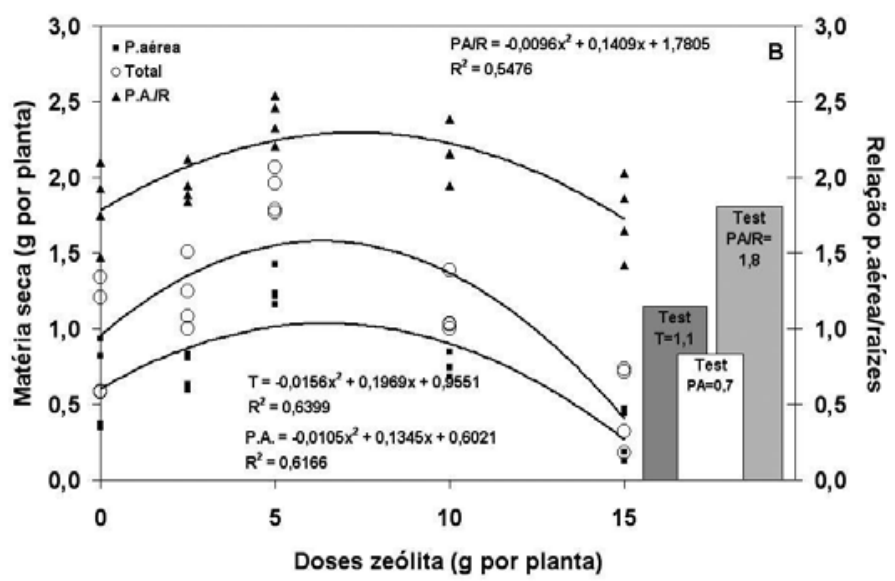

FIGURA 1- Produção de matéria seca pelas folhas, caule e raízes (A), pela parte aérea, produção total e razão parte aérea/raízes (B) do porta-enxerto limoeiro 'Cravo', aos 93 dias de cultivo, em função das doses de concentrado zeolítico enriquecido com $\mathrm{N}, \mathrm{P}$ e K. As barras indicam os valores médios observados para a testemunha absoluta.

A
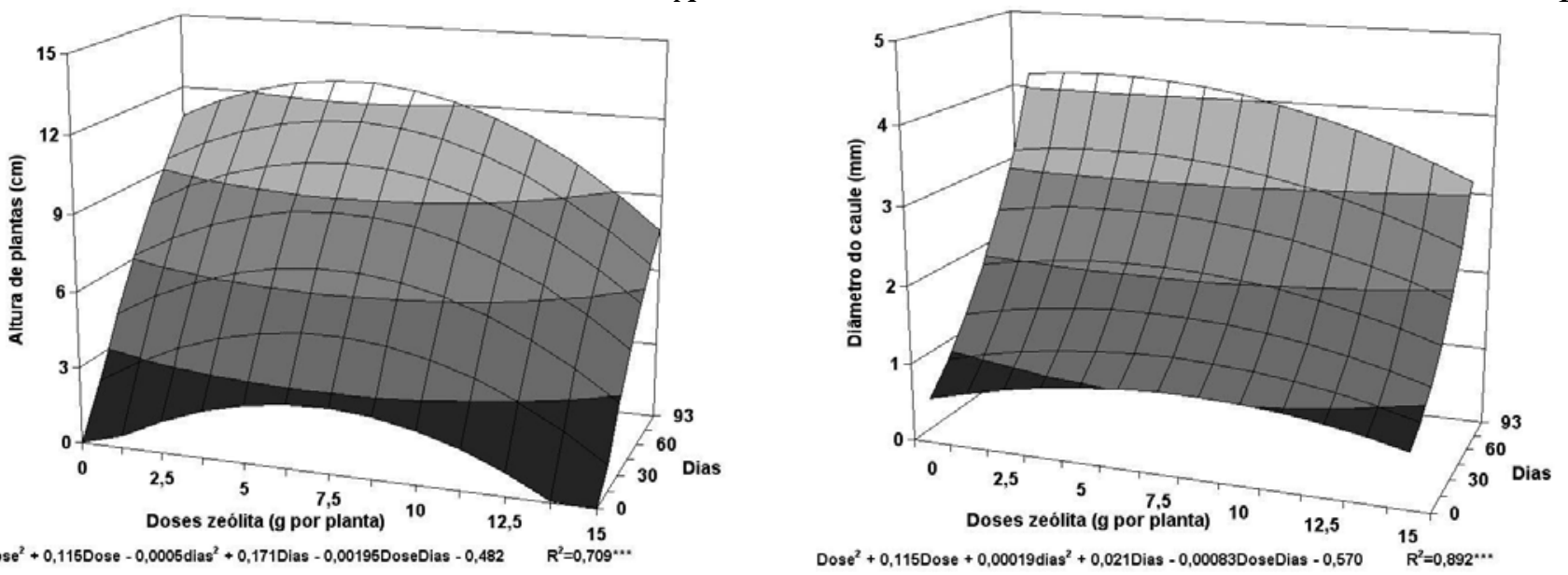

FIGURA 2 - Altura de plantas (A) e diâmetro do caule (B) do porta-enxerto limoeiro ‘Cravo', ao longo dos 93 dias de cultivo, em função das doses de concentrado zeolítico enriquecido com N, P e K. 


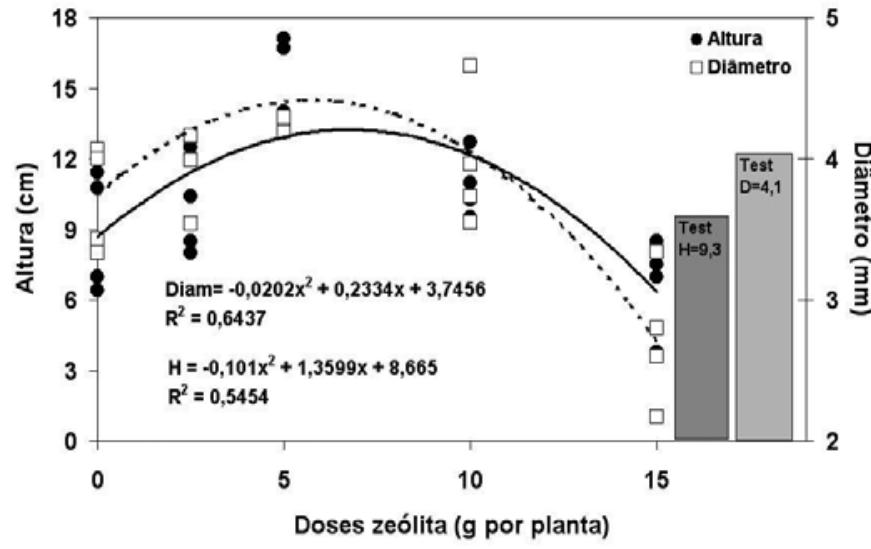

FIGURA 3 - Altura e diâmetro do caule do porta-enxerto limoeiro 'Cravo', aos 93 dias de cultivo, em função das doses de concentrado zeolítico enriquecido com $\mathrm{N}, \mathrm{P}$ e K. As barras indicam os valores médios observados para a testemunha absoluta.

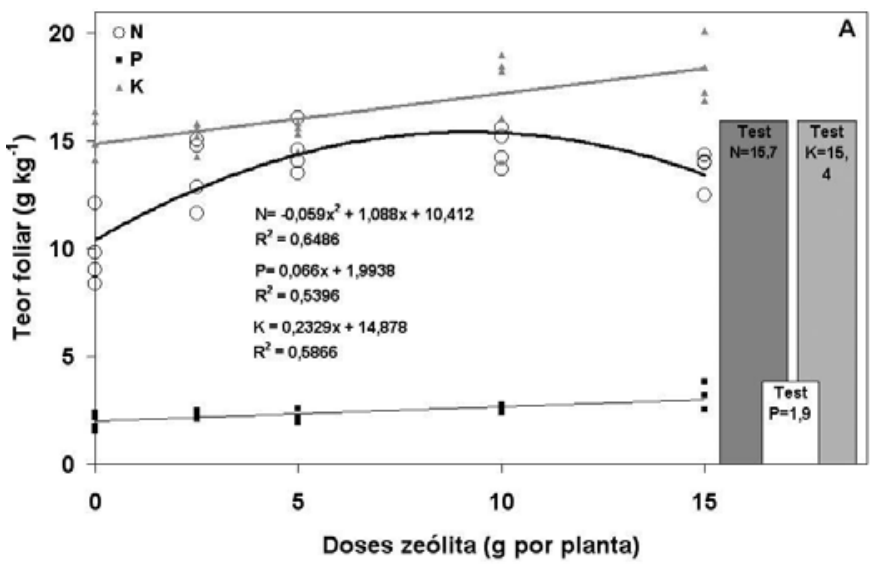

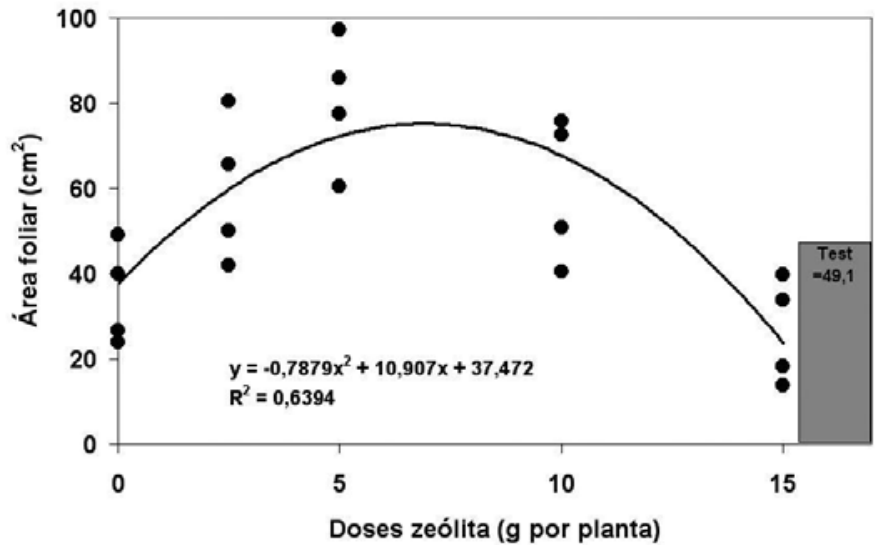

FIGURA 4- Área foliar $\left(\mathrm{cm}^{2}\right)$ do porta-enxerto limoeiro 'Cravo', aos 93 dias de cultivo, em função das doses de concentrado zeolítico enriquecido com N, P e K. As barras indicam os valores médios observados para a testemunha absoluta.

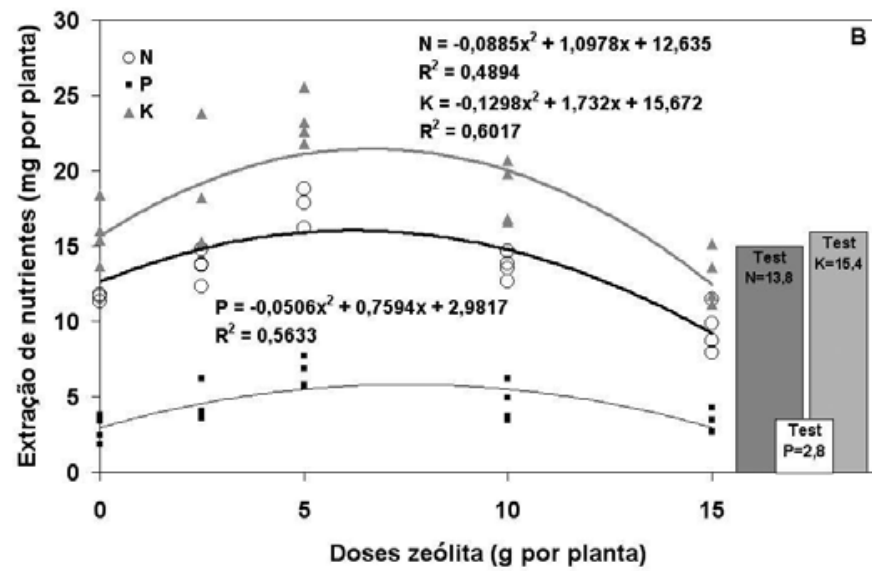

FIGURA 5 - Teores foliares (A) e extrações (B) de N, Pe K pelo porta-enxerto limoeiro 'Cravo', aos 93 dias de cultivo, em função das doses de concentrado zeolítico enriquecido com N, P e K. As barras indicam os valores médios observados para a testemunha absoluta.
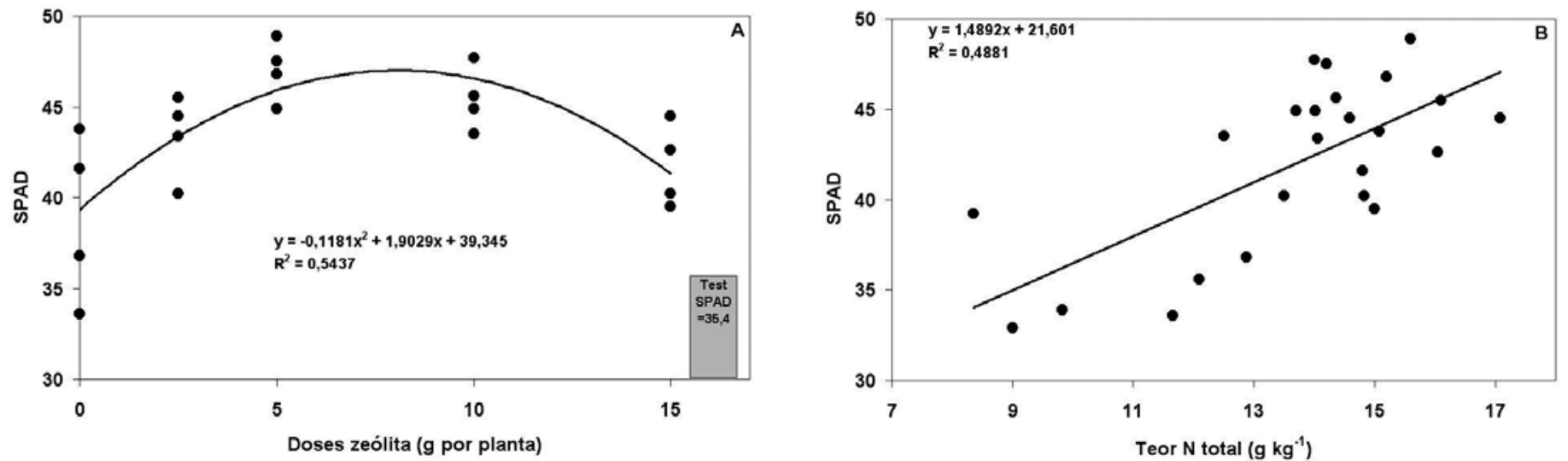

FIGURA 6 - Teores de clorofila (A), indicados pelas leituras SPAD, do porta-enxerto limoeiro 'Cravo', aos 93 dias de cultivo, em função das doses de concentrado zeolítico enriquecido com N, P e K, e a correlação entre os teores de $\mathrm{N}$ e as leituras SPAD nas folhas do limoeiro 'Cravo' (B). A barra indica os valores médios observados para a testemunha absoluta. 


\section{CONCLUSÕES}

1- Os resultados indicaram que o fornecimento de $\mathrm{N}, \mathrm{Pe}$ K através do mineral zeólita enriquecido com NPK, adicionado ao substrato orgânico, comprovou ser alternativa viável para a obtenção de porta-enxertos no sistema de produção em ambiente protegido.

2- A adição de 6,4 g do concentrado zeolítico enriquecido com NPK aumentou significativamente a produção de matéria seca, área foliar, altura e diâmetro de caule. Este aumento foi de $37,5 \%$ em relação à testemunha que não recebeu o concentrado zeolítico enriquecido com NPK.

3- Houve aumentos nos teores e extração de N, P e K com o fornecimento da zeólita enriquecida. As leituras dos teores de clorofila relacionaram-se com os teores de $\mathrm{N}$, indicando ser esta uma alternativa para o diagnóstico do estado nutricional para a cultura.

\section{AGRADECIMENTOS}

À FINEP, através do CT Mineral, pelo financiamento do trabalho.

\section{REFERÊNCIAS}

ALLEN, E.; MING, D.; HOSSNER, L.; HENNINGER, D.; GALINDO, C. Growth and nutrient uptake of wheat in a clinoptilolite-phosphate rock substrate. Agronomy Journal, Madison, v. 87, n. 6, p. 1052-1059, 1995.

BARBARICK, K. A.; LAI, T. M.; EBERL, D. D. Exchange fertilizer (phosphate rock plus ammonium-zeolite) effects on sorghumsudangrass. Soil Science Society of America Journal, Madison, v. 54, n. 3, p. 911-916, 1990.

BERNARDI, A. C. C.; CARMELLO, Q. A. C.; CARVALHO, S. A. Desenvolvimento de mudas de citros cultivadas em vaso em resposta à adubação NPK. Scientia Agricola, Piracicaba, v. 57, n. 4, p. 733-738, 2000a.

BERNARDI, A. C. C.; CARMELLO, Q. A. C.; CARVALHO, S. A. Macronutrientes em mudas de citros cultivadas em vasos em resposta à adubação NPK. Scientia Agricola, Piracicaba, v. 57, n. 4, p. 761-767, 2000b.

CARMO, C. A. F. S.; ARAÚJO, W. S.; BERNARDI, A. C. C.; SALDANHA, M. F. C. Métodos de análise de tecidos vegetais utilizados na Embrapa Solos. Rio de Janeiro, Embrapa Solos, 2000. 41p. (Circular Técnica, 6).

CARVALHO, S. A. Estratégias para estabelecimento e manutenção de matrizes, borbulheiras e viveiro de citros em ambiente protegido. In: SEMINÁRIO INTERNACIONAL DE CITROS - TRATOS CULTURAIS, 5., Bebedouro, 1998. Anais... Bebedouro: Fundação Cargill, 1998. p.67-101.
CARVALHO, S. A.; MATTOS JÚNIOR, D.; SOUZA, M. Efeito do $\mathrm{KNO}_{3}$ nos teores de macronutrientes na matéria seca total de porta-enxertos cítricos produzidos em bandejas. Bragantia, Campinas, v.59, n. 1, p. 89-94, 2000.

\section{CATI. COORDENADORIA DE ASSISTÊNCIA TÉCNICA}

INTEGRAL. Normas para produção de muda certificada de citros. Laranja, Cordeirópolis, v. 19, n. 2, p.67-101, 1998.

COETZEE, J. G. K.; ESSELEN, L.; VAN ROOYEN, A. Fertilization of nursery trees - alternative method. In: WORLD CONGRESS OF THE INTERNATIONAL SOCIETY OF CITRUS NURSERYMEN, 2., 1993, Pietermaritzburg. Proceedings... Pietermaritzburg: International Society of Citrus Nurserymen, 1993. p.143-150.

CRESTANA, S.; GUIMARÃES, M. F.; JORGE, L. A. C.; RALISCH, R.; TOZZI, C. L.; TORRENETO, A.; VAZ, C. M. P. Avaliação da distribuição de raízes no solo auxiliada por processamento de imagens digitais. Revista Brasileira de Ciência do Solo, Campinas, v. 18, n. 3, p. 365-371, 1994.

DECARLOS NETO, A.; SIQUEIRA, D. L.; PEREIRA, P. R. G.; VENEGAS, V. H. A. Crescimento de porta-enxertos de citros produzidos em tubetes e influenciados por doses de N. Revista Brasileira de Fruticultura, Jaboticabal, v. 24, n. 1, p. 199-203, 2002.

EMBRAPA. Centro Nacional de Pesquisa de Solos. Manual de métodos de análise de solo. Rio de Janeiro: EMBRAPA/CNPS, 1997. 212 p. (Documentos, 1).

ESPOSTI, M. D. D.; SIQUEIRA, D. L. Doses de uréia no crescimento de porta-enxertos de citros produzidos em recipientes. Revista Brasileira de Fruticultura, Jaboticabal, v.26, n.1,p.136-139, 2004.

ESPOSTI, M. D. D.; SIQUEIRA, D. L.; PEREIRA, P. R. G.; VENEGAS, V. H. A.; SALOMÃO, L. C. C.; MACHADO FILHO, J. A. Assessment of nitrogenized nutrition of citrus rootstocks using chlorophyll concentrations in the leaf. Journal of Plant Nutrition, New York, v.26, n.6, p. 1287-1299, 2003.

HARLAND, J.; LANE, S.; PRICE, D. Further experiences with recycled zeolite as a substrate for the sweet pepper crop. Acta Horticulturae, The Hague, n.481, p.187-194, 1999.

LEGGO, P. J. An investigation of plant growth in an organozeolitic substrate and its ecological significance. Plant and Soil, The Hague, v. 219, n. 1-2, p. 135-146, 2000.

MALAVOLTA, E.; VITTI, G. C.; OLIVEIRA, S. A. Avaliação do estado nutricional das plantas: princípios e aplicações. 2.ed. Piracicaba: POTAFÓS, 1997.319p. 
MERCADET, A.; GONZALEZ-ABREU, A.; MARTINEZ, J. A.; RUMEO, J. L.; ROMEU, P.; RODRIGUEZ, G. First experience in using zeolite to produce seedlings of Eucalyptus pellita for reforestation of the serpentine savanna in Camaguey. Revista Forestal Baracoa, La Habana, v. 20, n. 2, p. 89-93, 1990 b.

MERCADET, A.; GONZALEZ-ABREU, A.; MARTINEZ, J. A.; RUMEO, J.L.; ROMEU, P.; RODRIGUEZ, G. First experience in using zeolite to produce seedlings of Pinus caribaea var. caribaea for reforestation of the serpentine savanna in Camaguey. Revista Forestal Baracoa, La Habana, v. 20, n. 2, p. 83-87, 1990a.

MILLER, J. E.; HOFMAN, P. J.; BERRY, R. K. Physiological and nutritional responses of five citrus rootstocks to potassium. Journal of the Southern African Society for Horticultural Sciences, Pietermaritzburg, v.3, n.1, p.20-23, 1993.

MUMPTON, F.A. La roca magica: Uses of natural previous zeolites in agriculture and industry. Proceedings of National Academy of Sciences of the United States of America, Washington, v.96 n.7, p.3463-3470, 1999.

PICKERING, H. W.; MENZIES, N. W.; HUNTER, M. N. Zeolite/ rock phosphate - a novel slow release phosphorus fertiliser for potted plant production. Scientia Horticulturae, Amsterdam, v. 94, n. 3-4, p. 333-343, 2002.
REZENDE, L. P.; AMARAL, A. M.; CARVALHO, S. A.; SOUZA, M. Volume do substrato e superfosfato simples na formação do limoeiro 'Cravo' em vasos. I. Efeitos no crescimento vegetativo. Laranja, Cordeirópolis, v. 16, n. 2, p. 155-164, 1995.

REZENDE, N. G. A. M.; ANGÉLICA, R. S. Sedimentary zeolites in Brazil. Mineralogica et Petrographica Acta, Bologna, v. 42, p. 71-82, 1991.

RUSCHEL, J.; CARMELLO, Q. A. C.; BERNARDI, A. C. C.; CARVALHO, S. A.; MATTOS JR., D. Leaf nutrient contents of rangpur lime rootstock as afected by $\mathrm{N}, \mathrm{P}, \mathrm{K}, \mathrm{Ca}$ and $\mathrm{S}$ fertilization. Scientia Agricola, Piracicaba, v. 61, n. 5, p. 501-506, 2004.

SCIVITTARO, W. B.; OLIVEIRA, R. P.; MORALES, C. F. G.; RADMANN, E. B. Adubação nitrogenada na formação de portaenxertos de limoeiro 'Cravo' em tubetes. Revista Brasileira de Fruticultura, Jaboticabal, v. 26, n. 1, p. 131-135, 2004.

WILLIAMS, K. A.; NELSON, P. V. Using precharged zeolite as a source of potassium and phosphate in a soilless container medium during potted chrysanthemum production. Journal of the American Society for Horticultural Science, Alexandria, v.122, n.5, p.703-708, 1997. 